\title{
The correlation between polymorphisms in the XPC gene and glioma susceptibility in a Chinese pediatric population
}

\author{
Zhuorong Zhang ${ }^{1 \#}$, Yihuan Huang ${ }^{1 \#}$, Honghao Chen ${ }^{1 \#}$, Ping Wu ${ }^{1}$, Zhijian Deng ${ }^{1}$, Gaoyan Deng ${ }^{1}$, \\ Yongqin Zheng ${ }^{1}$, Guoyuan $\mathrm{Li}^{1}$, Li Yuan ${ }^{2}$, Yingyi $\mathrm{Xu}^{3}$ \\ ${ }^{1}$ Department of Comprehensive and Emergency Surgery, Guangzhou Women and Children's Medical Center, Guangzhou Medical University, \\ Guangzhou, China; ${ }^{2}$ Department of Pathology, Guangzhou Women and Children's Medical Center, Guangzhou Medical University, Guangzhou, \\ China; ${ }^{3}$ Department of Anesthesiology, Guangzhou Women and Children's Medical Center, Guangzhou Medical University, Guangzhou, China \\ Contributions: (I) Conception and design: Y Xu, Z Deng, L Yuan; (II) Administrative support: Y Xu, L Yuan; (III) Provision of study materials or \\ patients: Z Zhang; (IV) Collection and assembly of data: Z Zhang, H Chen, P Wu, Y Huang, G Li; (V) Data analysis and interpretation: Y Xu, Y \\ Huang; (VI) Manuscript writing: All authors; (VII) Final approval of manuscript: All authors. \\ \#These authors contributed equally to this work. \\ Correspondence to: Yingyi Xu. Department of Anesthesiology, Guangzhou Women and Children's Medical Center, Guangzhou Medical University, \\ 9 Jinsui Road, Guangzhou 510623, China. Email: 513438980@qq.com; Yuan Li. Department of Pathology, Guangzhou Women and Children's \\ Medical Center, Guangzhou Medical University, 9 Jinsui Road, Guangzhou 510623, China. Email: lizzyklarck@126.com.
}

Background: A previous study revealed that single nucleotide polymorphisms (SNPs) in coding genes play a key role in tumorigenesis, genetic disorders, and drug resistance. Xeroderma pigmentosum group C $(X P C)$ protein is a key DNA damage recognition factor that is required for maintaining the genomic stability. However, the correlation between $X P C$ polymorphisms and glioma susceptibility is still unclear. Hence, this study aimed to investigate the correlation between $X P C$ polymorphisms and pediatric glioma susceptibility.

Methods: A total of 399 participants (171 glioma patients and 228 controls) were enrolled to evaluate the correlation between XPC polymorphism and pediatric glioma susceptibility. The count data of two groups was analyzed by chi-squared $\left(\chi^{2}\right)$ test. Moreover, logistic regression was used to assess the strength of XPC polymorphisms associated with glioma susceptibility.

Results: We identified that XPC rs1870134 G>C reduced pediatric glioma susceptibility. Compared to participants with rs1870134 GG/GC genotypes, those with rs1870134 CC genotype had a significantly lower risk for glioma [adjusted odds ratio $(\mathrm{AOR})=0.10,95 \%$ confidence interval (CI): 0.01 to $0.78, \mathrm{P}=0.028$ ]. Patients with 4-5 genotypes have higher risk of glioma than those with 0-3 genotypes (AOR =1.59, 95\% CI: 1.04 to $2.43, \mathrm{P}=0.031$ ). The stratified analysis showed that the risky effects of rs2228000 CT/TT genotypes and rs2229090 GC/CC genotypes were more predominant among children aged $\geq 60$ months, astrocytic tumors, and clinical stage I.

Conclusions: We found for the first time that XPC polymorphisms had a statistically significant correlation with pediatric glioma susceptibility in a Chinese population. The XPC rs2228000 CT/TT and rs2229090 GC/CC genotypes could both increase the risk of pediatric glioma in subgroups with females, astrocytic tumors, and clinical stage I. The XPC polymorphism has potential to be a useful adjunct method to screen pediatric glioma.

Keywords: Pediatric glioma; xeroderma pigmentosum group C (XPC); susceptibility; polymorphism.

Submitted Jun 04, 2021. Accepted for publication Jul 15, 2021.

doi: $10.21037 /$ tp-21-301

View this article at: https://dx.doi.org/10.21037/tp-21-301 


\section{Introduction}

Brain glioma is a common type of primary malignant tumor accounting for $40-50 \%$ of central nervous system (CNS) tumors in adults and children (1). The average incidence rate of glioma is 6.6 per 100,000 individuals (2), and the incidence is even higher in children. Unfortunately, from 2005 to 2018, the incidence and mortality of glioma in China showed an upward trend $(3,4)$. Although diagnosis and treatment levels have been improved to some extent, the prognosis of glioma patients is still not satisfactory $(5,6)$, especially for diffuse midline gliomas $(7)$. To date, pediatric high-grade glioma is the main cause of cancer death in children, with a 5 -year survival rate of less than $20 \%$ (8). Therefore, exploration of the related risk factors of pediatric glioma is of great significance for improving the prognosis of glioma.

Tumor susceptibility refers to the tendency of different populations and individuals to suffer from certain malignant tumors under the influence of external environment due to different genetic structure. Single nucleotide polymorphism (SNP), the most common type of DNA polymorphism, is the substitution of a single nucleotide in a genome (9). Increasing studies have shown that SNPs are involved in the occurrence of various diseases, such as type 2 diabetes mellitus (T2DM) and tumors (10,11). They have been used in the early diagnosis of a variety of tumors, such as tumor necrosis factor- $\alpha$ (TNF- $\alpha)(11,12)$. Moreover, SNPs can also be used as an important indicator to identify tumorgenetically susceptible populations.

Previous studies have confirmed that the DNA repair system plays a key role in maintaining the integrity of the cellular genome (13). In DNA repair pathways, nucleotide excision repair (NER) functions through a "cut-and-patch" mechanism by excising and removing a short fragment of DNA of about 24-32 nucleotides containing the damaged nucleotides. The DNA damage repair pathway can maintain the stability of the cell genome and prevent gene mutation and tumorigenesis (14). The xeroderma pigmentosum group $\mathrm{C}(X P C)$ gene is located on chromosome 3 p25 and codes for a 940 amino acid protein. It plays a key role in initiating the NER pathway by associating with HR23B to form a complex that recognizes sites of damaged DNA (15). The XPC gene may also actively participate in base excision repair (BER) by ablating $\mathrm{G} / \mathrm{T}$ mismatches to suppress spontaneous mutations. This DNA repair is an important way of maintaining the stability of genetic information in the human body (16). There have been great concerns that an association between XPC polymorphisms and risk of diseases including chronic myeloid leukemia advanced non-small cell lung cancer $(17,18)$. Previous studies have reported about the correlation between polymorphisms in the XPC gene and genetic susceptibility (19), but there is no research on the relationship between XPC gene and genetic susceptibility of glioma. Especially, the correlation between $X P C$ polymorphisms and pediatric glioma is still unclear. Thus, this case-control study predominantly focused on analyzing the correlation between XPC gene polymorphism and glioma susceptibility in Chinese children through a population of 339 patients. We present the following article in accordance with the STREGA reporting checklist (available at https://dx.doi.org/10.21037/tp-21-301).

\section{Methods}

\section{Study subjects}

In this study, a total of 171 glioma patients and 228 tumorfree controls from South China were enrolled. Healthy children were included in the study as the controls and matched with contemporaneous cases by age and gender. We collected clinical information including patients' age, gender, and clinical stages. All procedures performed in this study involving human participants were in accordance with the Declaration of Helsinki (as revised in 2013). The study was approved by the Ethics Committee of Guangzhou Women and Children's Medical Center (No. 2016021650) and informed consent was taken from all the patients.

\section{Polymorphism analysis}

Firstly, the functional XPC gene polymorphisms were retrieved from dbSNP database (https://www.ncbi.nlm. nih.gov/snp/) and SNPinfo (https://snpinfo.niehs.nih. gov/snpinfo/snpfunc.html). The screening criteria were as the previous study described (20). Notably, we selected SNPs from noncoding region, UTR (5' and $\left.3^{\prime}\right)$ and introns regions, and finally obtained five SNPs including rs2228001 $\mathrm{A}>\mathrm{C}, \mathrm{rs} 2228000 \mathrm{C}>\mathrm{T}, \mathrm{rs} 2607775 \mathrm{C}>\mathrm{G}, \mathrm{rs} 1870134 \mathrm{G}>\mathrm{C}$, and rs2229090 G>C.

Secondly, $2 \mathrm{~mL}$ of peripheral blood was drawn from each participant, and genomic DNA was isolated using the TIANamp Blood DNA Kit (TianGen Biotech Co., Ltd., Beijing, China). The XPC genotyping was conducted by TaqMan real-time quantitative polymerase chain reaction (qPCR). In addition, to make the results reliable, another 
$10 \%$ of patients' samples were randomly selected for secondary testing to ensure that the results of all samples were consistent.

\section{Statistical analysis}

All data were analyzed using SAS software (version 9.4 SAS Institute Inc., Cary, NC, USA). The Hardy-Weinberg equilibrium (HWE) of all SNPs in the controls was tested by the goodness-of-fit chi-squared $\left(\chi^{2}\right)$ test, and the count data of two groups was analyzed by $\chi^{2}$ test. Logistic regression was further used to analyze the correlation between $X P C$ genotypes and glioma susceptibility. The odds ratio $(\mathrm{OR}), 95 \%$ confidence interval $(\mathrm{CI})$, and the $\mathrm{P}$ value were corrected for age and gender. A two-sided $\mathrm{P}<0.05$ was deemed statistically significant.

\section{Results}

\section{Baseline characteristics}

In this case-control study, a total of 399 age/gendermatched participants (171 cases with glioma and 228 nontumor controls) were enrolled. The clinicopathological characteristics are summarized in Table S1. The mean ages of cases with glioma and controls were $63.40 \pm 47.72$ and $52.41 \pm 32.65$ months, respectively. There were more males in this study than female participants $(56.4 \% v s$. 43.6\%). However, there were no statistical differences in age $(\mathrm{P}=0.623)$ and gender $(\mathrm{P}=0.190)$. Among the 171 participants with glioma, there were $131(76.6 \%)$ cases of glioma grade I-II. The two groups did not statistically differ in age $(\mathrm{P}=0.623)$ and gender $(\mathrm{P}=0.190)$.

\section{The correlation between XPC polymorphisms and glioma susceptibility in Chinese pediatric population}

All participants were genotyped. The genotype frequency and percentage of XPC polymorphism are shown in Table 1. The genotype distributions of five SNPs were consistent with HWE in controls $(\mathrm{P}=0.845$ for rs2228001 $\mathrm{A}>\mathrm{C}, \mathrm{P}=0.764$ for $\mathrm{rs} 2228000 \mathrm{C}>\mathrm{T}, \mathrm{P}=0.583$ for $\mathrm{rs} 2607775$ $\mathrm{C}>\mathrm{G}, \mathrm{P}=0.121$ for $\mathrm{rs} 1870134 \mathrm{G}>\mathrm{C}, \mathrm{P}=0.215$ for $\mathrm{rs} 2229090$ $\mathrm{G}>\mathrm{C})$. From the single-locus analysis, we found that $X P C$ rs1870134 G>C was significantly correlated with low risk glioma susceptibility. Compared to participants with rs1870134 GG/GC genotypes, those with rs1870134 CC genotype had a remarkably lower risk for glioma [adjusted
OR $(\mathrm{AOR})=0.10,95 \% \mathrm{CI}: 0.01$ to $0.78, \mathrm{P}=0.028]$. The distribution of XPC rs1870134 genotype was different between the cases and the control group. In the cases group, participants with GG, GC, and CC genotypes were $116(67.84 \%), 54(31.58 \%)$, and 1 (0.58\%). However, participants with GG, GC, and CC genotypes were $146(64.04 \%), 68(29.82 \%)$, and $14(6.14 \%)$ in the control group. The proportions of CC genotype in the two groups were significantly different. The above results suggested that XPC rs1870134 CC genotype may reduce the risk of pediatric glioma in recessive models.

Next, we further assessed the combined effect of the five genotypes of $X P C$ on glioma susceptibility. The results revealed that patients with 4-5 genotypes were at remarkably higher risk of developing glioma than those with $0-3$ genotypes (AOR $=1.59,95 \%$ CI: 1.04 to 2.43, $\mathrm{P}=0.031)$.

\section{Stratification analysis}

We also further assessed the effects of rs2228000 C>T polymorphism, rs2229090 G>C polymorphism, and combined risk genotypes on the glioma risk in different subgroups. Table 2 summarizes the genotypes frequencies in different subgroups. After adjustment for potential confounders, we observed that rs2228000 C>T polymorphism increased the risk of glioma susceptibility in several subgroups (females subgroup: CC vs. CT/TT: $\mathrm{AOR}=1.93,95 \% \mathrm{CI}: 1.01$ to $3.67, \mathrm{P}=0.047$; astrocytic tumors subgroup: CC $v s$. CT/TT: AOR $=1.73,95 \% \mathrm{CI}$ : 1.07 to $2.80, \mathrm{P}=0.026$; clinical stage I subgroup: $\mathrm{CC} v$ s. CT/TT: $\mathrm{AOR}=1.96,95 \% \mathrm{CI}: 1.16$ to $3.29, \mathrm{P}=0.012$ ). In addition, similar results were obtained in rs2229090 $\mathrm{G}>\mathrm{C}$ polymorphism (females subgroup: GG vs. GC/CC: $\mathrm{AOR}=2.13,95 \% \mathrm{CI}: 1.10$ to $4.11, \mathrm{P}=0.025$; astrocytic tumors subgroup: GG vs. GC/CC: $\mathrm{AOR}=2.05,95 \% \mathrm{CI}$ : 1.24 to $3.38, \mathrm{P}=0.005$; clinical stage I subgroup: $\mathrm{GG} v s$. GC/ CC: $\mathrm{AOR}=2.31,95 \% \mathrm{CI}: 1.34$ to $3.98, \mathrm{P}=0.003$; clinical stage II subgroup: GG vs. GC/CC: AOR $=1.63,95 \% \mathrm{CI}$ : 1.02 to $2.61, \mathrm{P}=0.041)$.

When the risk genotypes were combined, we found that patients with 4-5 risk genotypes had higher risk of glioma than those with $0-3$ risk genotypes among the following subgroup: age $\geq 60$ months (AOR $=1.86,95 \%$ CI: 1.02 to $3.38, \mathrm{P}=0.043$ ), females ( $\mathrm{AOR}=2.34,95 \% \mathrm{CI}$ : 1.22 to $4.50, \mathrm{P}=0.011$ ), astrocytic tumors ( $\mathrm{AOR}=2.07,95 \%$ CI: 1.27 to $3.37, \mathrm{P}=0.004$ ), clinical stage $\mathrm{I}(\mathrm{AOR}=2.38,95 \%$ CI: 1.40 to $4.05, \mathrm{P}=0.002)$ and clinical stage I + II group 
Table 1 Association between $X P C$ gene polymorphisms and glioma susceptibility in Chinese children

\begin{tabular}{|c|c|c|c|c|c|c|c|}
\hline Genotype & Cases $(n=171), n(\%)$ & Controls (n=228), n (\%) & $P$ value ${ }^{a}$ & Crude OR (95\% Cl) & $P$ value & $\operatorname{AOR}(95 \% \mathrm{Cl})^{\mathrm{b}}$ & $P$ value ${ }^{b}$ \\
\hline AA & $62(36.26)$ & $89(39.04)$ & & 1.00 & & 1.00 & \\
\hline$A C$ & $87(50.88)$ & $108(47.37)$ & & $1.16(0.75-1.78)$ & 0.508 & $1.10(0.71-1.70)$ & 0.672 \\
\hline $\mathrm{CC}$ & $22(12.87)$ & $31(13.60)$ & & $1.02(0.54-1.92)$ & 0.954 & $0.94(0.49-1.79)$ & 0.849 \\
\hline Dominant & $109(63.74)$ & $139(60.96)$ & 0.571 & $1.13(0.75-1.70)$ & 0.571 & $1.06(0.70-1.61)$ & 0.773 \\
\hline Recessive & $149(87.13)$ & $197(86.40)$ & 0.831 & $0.94(0.52-1.69)$ & 0.832 & 0.89 (0.49-1.62) & 0.702 \\
\hline \multicolumn{8}{|c|}{ rs2228000 C>T (HWE =0.764) } \\
\hline $\mathrm{CC}$ & 57 (33.33) & $92(40.35)$ & & 1.00 & & 1.00 & \\
\hline Additive & & & 0.237 & $1.19(0.89-1.59)$ & 0.237 & $1.21(0.90-1.62)$ & 0.215 \\
\hline Dominant & $114(66.67)$ & $136(59.65)$ & 0.152 & 1.35 (0.90-2.05) & 0.152 & 1.36 (0.89-2.06) & 0.154 \\
\hline Recessive & $145(84.80)$ & $196(85.96)$ & 0.743 & $1.10(0.63-1.92)$ & 0.742 & $1.14(0.65-2.01)$ & 0.653 \\
\hline \multicolumn{8}{|c|}{ rs2607775 C>G (HWE =0.583) } \\
\hline $\mathrm{CC}$ & $164(95.91)$ & $212(92.98)$ & & 1.00 & & 1.00 & \\
\hline CG & $6(3.51)$ & $16(7.02)$ & & $0.49(0.19-1.27)$ & 0.139 & $0.47(0.18-1.24)$ & 0.125 \\
\hline GG & $1(0.58)$ & $0(0.00)$ & & - & - & - & - \\
\hline Additive & & & 0.352 & $0.67(0.29-1.56)$ & 0.355 & $0.67(0.28-1.57)$ & 0.354 \\
\hline $\mathrm{CC}$ & $1(0.58)$ & $14(6.14)$ & & $0.09(0.01-0.69)^{\star}$ & $0.021^{*}$ & $0.10(0.01-0.78)^{\star}$ & $0.028^{*}$ \\
\hline Additive & & & 0.098 & $0.74(0.51-1.06)$ & 0.099 & $0.75(0.52-1.09)$ & 0.129 \\
\hline Dominant & $55(32.16)$ & $82(35.96)$ & 0.429 & $0.84(0.56-1.28)$ & 0.429 & $0.86(0.56-1.31)$ & 0.473 \\
\hline Recessive & $170(99.42)$ & $214(93.86)$ & 0.004 & $0.09(0.01-0.69)^{\star}$ & $0.021^{*}$ & $0.10(0.01-0.78)^{\star}$ & $0.028^{*}$ \\
\hline \multicolumn{8}{|c|}{ rs2229090 G>C (HWE =0.215) } \\
\hline GG & $51(29.82)$ & $88(38.60)$ & & 1.00 & & 1.00 & \\
\hline GC & 88 (51.46) & $100(43.86)$ & & $1.52(0.97-2.38)$ & 0.068 & $1.55(0.99-2.44)$ & 0.058 \\
\hline $\mathrm{CC}$ & $32(18.71)$ & $40(17.54)$ & & $1.38(0.77-2.46)$ & 0.275 & $1.43(0.79-2.56)$ & 0.236 \\
\hline Additive & & & 0.165 & $1.22(0.92-1.62)$ & 0.166 & $1.24(0.93-1.65)$ & 0.138 \\
\hline Dominant & $120(70.18)$ & $140(61.40)$ & 0.069 & $1.48(0.97-2.26)$ & 0.069 & 1.52 (0.99-2.33) & 0.057 \\
\hline Recessive & 139 (81.29) & $188(82.46)$ & 0.764 & $1.08(0.65-1.81)$ & 0.763 & $1.10(0.66-1.86)$ & 0.712 \\
\hline
\end{tabular}

Table 1 (continued) 
Table 1 (continued)

\begin{tabular}{|c|c|c|c|c|c|c|c|}
\hline Genotype & Cases $(n=171), n(\%)$ & Controls (n=228), n (\%) & $P$ value ${ }^{a}$ & Crude OR $(95 \% \mathrm{Cl})$ & $P$ value & $\operatorname{AOR}(95 \% \mathrm{Cl})^{b}$ & $P$ value ${ }^{b}$ \\
\hline \multicolumn{8}{|c|}{ Combined effect of risk genotypes $^{c}$} \\
\hline $0-3$ & $54(31.58)$ & $95(41.67)$ & & 1.00 & & 1.00 & \\
\hline $4-5$ & $117(68.42)$ & $133(58.33)$ & 0.039 & $1.55(1.02-2.35)^{\star}$ & $0.040^{*}$ & $1.59(1.04-2.43)^{*}$ & $0.031^{*}$ \\
\hline
\end{tabular}

( $\mathrm{AOR}=1.73,95 \% \mathrm{CI}: 1.09$ to $2.75, \mathrm{P}=0.020)$.

\section{Discussion}

Glioma is the most common intracranial malignant tumor, and the incidence of gliomas is rising worldwide (21-23). Increasing studies have revealed that mutations in different genes in glioma patients are closely correlated with gliomagenesis (24). Among them, SNP is the most common type of genetic mutation which alters single base pair in alleles either in or between individuals (25). There are only $0.1 \%$ differences between individual genomes, known as SNP, and these small differences between genomes determine the differences between individuals and are the main cause of genetic variation between individuals. The associations between genetic polymorphisms in XPC and glioma susceptibility remain largely unknown.

In this case-control study, we firstly assessed the correlation between XPC polymorphisms and glioma susceptibility in a Chinese pediatric glioma population. We found that XPC rs1870134 G>C was correlated with pediatric glioma susceptibility in recessive models. The $X P C$ rs1870134 CC genotype could reduce the risk of pediatric glioma. Additionally, rs2228000 CT/TT and rs2229090 GC/CC genotypes could increase the risk of pediatric glioma in subgroups with females, astrocytic tumors, and clinical stage I. These results suggest that $X P C$ polymorphisms may potentially act as biomarker for pediatric glioma diagnosis.

The XPC gene contains 16 exons and 15 introns, is located on the long arm of chromosome 3 , and encodes a 940 -amino acid protein (26), which is also the DNA recognition molecule of the NER-repair pathway. Previous studies have shown that $X P C$ protein forms a stable complex with HHR 23b protein and is mainly involved in the identification of DNA damage sites, and further initiates the repair of the NER pathway (27). Thus, XPC gene mutation could reduce its ability to repair. Increasing studies have shown that XPC polymorphism is correlated with susceptibility to prostate cancer, non-small cell lung cancer, colorectal cancer, and other diseases $(28,29)$. However, Hua et al. (30) reported that XPC gene rs1870134 G>C was not correlated with gastric cancer susceptibility in a southern Chinese population, which did not concur with our results. The inconsistent biological function of XPC rs1870134 G>C locus may be caused by different population types and kinds of tumor. In addition, genetic factors and living environment are also potential reasons. Lakkireddy reported that XPC Ala499Val (rs2228000 C>T) correlate is a high-risk polymorphism of chronic myeloid leukemia susceptibility, which was consistent with our results (18). Gil et al. found that the XPC rs279017 (i11C/A) genotype is associated with an increased risk of sporadic colorectal cancer, and the possible cause is that polymorphism at the $X P C$ intron 11 splicing receptor site increased the jump frequency of exon 12, leading to reduced DNA repair ability (31). Mathew et al. found that the Gln allele at Lys939Gln (rs2228001 A>C) is associated with Hepatocellular carcinoma susceptibility (32). The possible reason is that $X P C$ rs $2228001 \mathrm{~A}>\mathrm{C}$ is located on the proteincoding areas, and the $\mathrm{A} / \mathrm{C}$ transversions potentiate the change of encoded amino acid from lysine to glutamate (33). Notably, mutations that cause disease are not concentrated in the $X P C$ gene (34), a single amino acid change is enough to have a significant effect on the function of XPC (35). Khan $e t a l$. found that genotype A/A can reduce the repair ability of $X P C$ protein by about $50 \%$ (36).

This study had some considerable limitations. Firstly, was a case-control study based on a hospital population, and there may have been some participant selection bias. Secondly, only 399 participants were included in this study, so the sample size was not sufficiently large. It is necessary 


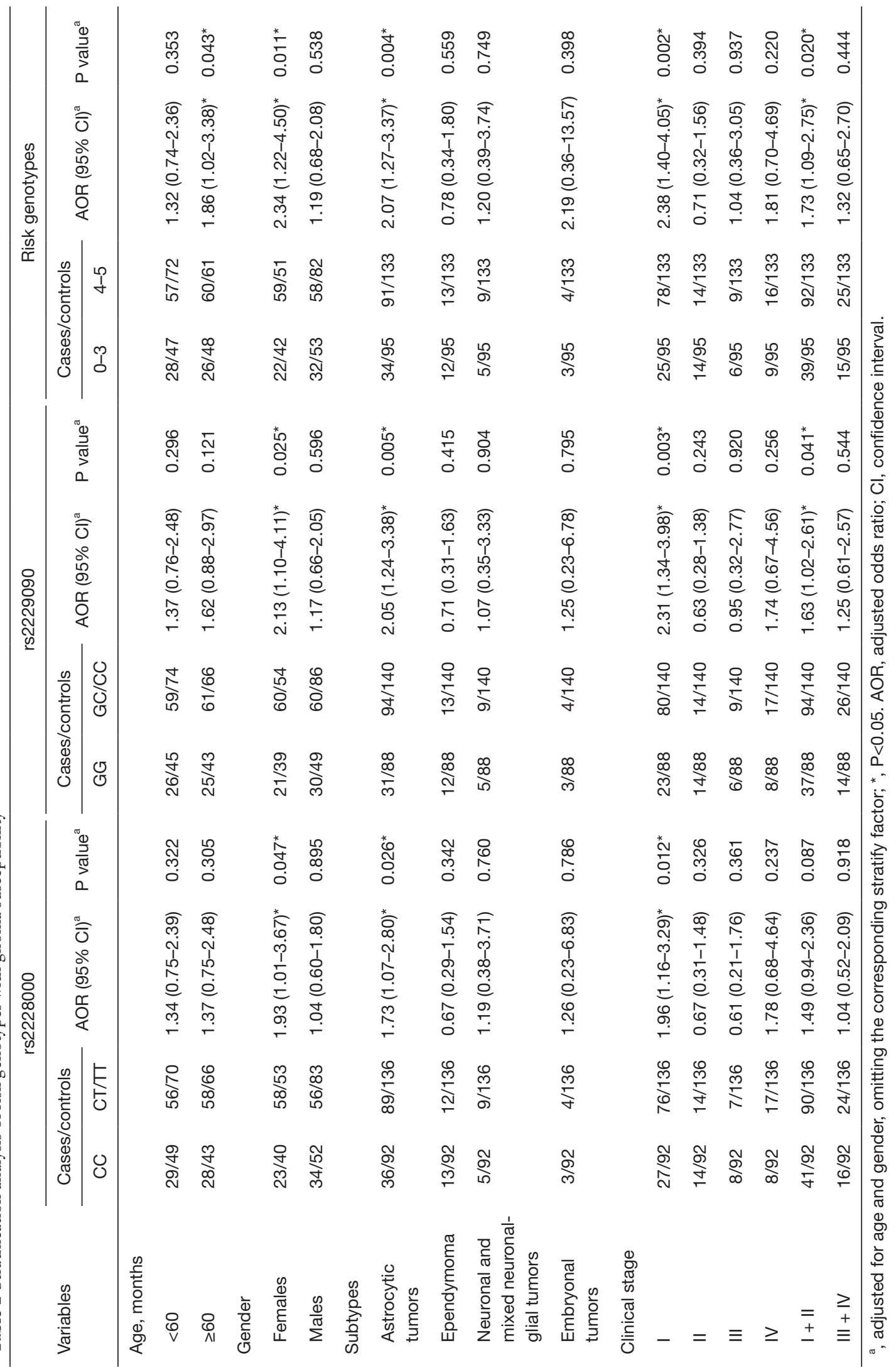


to further expand the sample size and involve different medical centers to verify the results. Thirdly, in the future, we should consider a broader range of risk factors that affect glioma susceptibility, such as environmental factors and ionizing radiation.

\section{Conclusions}

We found for the first time that XPC polymorphisms were statistically significantly correlated with pediatric glioma susceptibility in a Chinese population. The XPC rs1870134 CC genotype could reduce the risk of pediatric glioma. However, the rs2228001 A>C, rs2607775 C>G, rs2229090 $\mathrm{G}>\mathrm{C}$ polymorphisms of $X P C$ were not correlated with the risk of pediatric glioma. Additionally, rs2228000 CT/ TT and rs2229090 GC/CC genotypes could both increase the risk of pediatric glioma in subgroups with females, astrocytic tumors, and clinical stage I.

\section{Acknowledgments}

Funding: This study was supported by grants from Guangzhou Science and Technology Planning Project (202002030007).

\section{Footnote}

Reporting Checklist: The authors have completed the STREGA reporting checklist. Available at https://dx.doi. org/10.21037/tp-21-301

Data Sharing Statement: Available at https://dx.doi. org/10.21037/tp-21-301

Conflicts of Interest: All authors have completed the ICMJE uniform disclosure form (available at https://dx.doi. org/10.21037/tp-21-301). The authors have no conflicts of interest to declare.

Ethical Statement: The authors are accountable for all aspects of the work in ensuring that questions related to the accuracy or integrity of any part of the work are appropriately investigated and resolved. All procedures performed in this study involving human participants were in accordance with the Declaration of Helsinki (as revised in 2013). The study was approved by the Ethics Committee of Guangzhou Women and Children's Medical Center (No. 2016021650) and informed consent was taken from all the patients.

Open Access Statement: This is an Open Access article distributed in accordance with the Creative Commons Attribution-NonCommercial-NoDerivs 4.0 International License (CC BY-NC-ND 4.0), which permits the noncommercial replication and distribution of the article with the strict proviso that no changes or edits are made and the original work is properly cited (including links to both the formal publication through the relevant DOI and the license). See: https://creativecommons.org/licenses/by-nc-nd/4.0/.

\section{References}

1. Ostrom QT, Gittleman H, Liao P, et al. CBTRUS Statistical Report: Primary brain and other central nervous system tumors diagnosed in the United States in 20102014. Neuro Oncol 2017;19:v1-88.

2. Wu X, Ouyang $\mathrm{Y}$, Wang B, et al. Hypermethylation of the IRAK3-activated MAPK signaling pathway to promote the development of glioma. Cancer Manag Res 2020;12:7043-59.

3. Yang $M$, Guo W, Yang C, et al. Mobile phone use and glioma risk: a systematic review and meta-analysis. PLoS One 2017;12:e0175136.

4. Ostrom QT, Cote DJ, Ascha M, et al. Adult glioma incidence and survival by race or ethnicity in the United States from 2000 to 2014. JAMA Oncol 2018;4:1254-62.

5. Qu S, Li S, Hu Z. Upregulation of piezo1 is a novel prognostic indicator in glioma patients. Cancer Manag Res 2020;12:3527-36.

6. Qu S, Liu S, Qiu W, et al. Screening of autophagy genes as prognostic indicators for glioma patients. Am J Transl Res 2020;12:5320-31.

7. Mackay A, Burford A, Carvalho D, et al. Integrated molecular meta-analysis of 1,000 pediatric high-grade and diffuse intrinsic pontine glioma. Cancer Cell 2017;32:520-37.e5.

8. Huang TY, Piunti A, Qi J, et al. Effects of H3.3G34V mutation on genomic $\mathrm{H} 3 \mathrm{~K} 36$ and $\mathrm{H} 3 \mathrm{~K} 27$ methylation patterns in isogenic pediatric glioma cells. Acta Neuropathol Commun 2020;8:219.

9. Zhang H, Li X, He F, et al. Turn-off colorimetric sensor for sequence-specific recognition of single-stranded DNA based upon Y-shaped DNA structure. Sci Rep 2018;8:12021.

10. Gao K, Wang J, Li L, et al. Polymorphisms in four genes (KCNQ1 rs151290, KLF14 rs972283, GCKR rs780094 
and MTNR1B rs10830963) and their correlation with type 2 diabetes mellitus in Han Chinese in Henan Province, China. Int J Environ Res Public Health 2016;13:260.

11. Guo J, Meng H, Pei J, et al. Association between the TNF- $\alpha-238 G>A$ and TGF- $\beta 1$ L10P polymorphisms and breast cancer risk: a meta-analysis. Breast Care (Basel) 2011;6:126-9.

12. Hirschhorn JN, Daly MJ. Genome-wide association studies for common diseases and complex traits. Nat Rev Genet 2005;6:95-108.

13. Jiang M, Jia K, Wang L, et al. Alterations of DNA damage repair in cancer: from mechanisms to applications. Ann Transl Med 2020;8:1685.

14. Zhou Q, Yao X, Wu C, et al. Knockdown of ubiquitinspecific protease 53 enhances the radiosensitivity of human cervical squamous cell carcinoma by regulating DNA damage-binding protein 2. Technol Cancer Res Treat 2020;19:1533033820929792.

15. Pollet M, Shaik S, Mescher M, et al. The AHR represses nucleotide excision repair and apoptosis and contributes to UV-induced skin carcinogenesis. Cell Death Differ 2018;25:1823-36.

16. Shimizu Y, Iwai S, Hanaoka F, et al. Xeroderma pigmentosum group $\mathrm{C}$ protein interacts physically and functionally with thymine DNA glycosylase. EMBO J 2003;22:164-73.

17. Bushra MU, Rivu SF, Sifat AE, et al. Genetic polymorphisms of GSTP1, XRCC1, XPC and ERCC1: prediction of clinical outcome of platinum-based chemotherapy in advanced non-small cell lung cancer patients of Bangladesh. Mol Biol Rep 2020;47:7073-82.

18. Lakkireddy S, Aula S, Kapley A, et al. Association of DNA repair gene XPC Ala499Val (rs2228000 C>T) and Lys939Gln (rs2228001 A>C) polymorphisms with the risk of chronic myeloid leukemia: a case-control study in a South Indian population. J Gene Med 2021;23:e3339.

19. Yang ZH, Liang WB, Jia J, et al. The xeroderma pigmentosum group $\mathrm{C}$ gene polymorphisms and genetic susceptibility of nasopharyngeal carcinoma. Acta Oncol 2008;47:379-84.

20. He J, Qiu LX, Wang MY, et al. Polymorphisms in the XPG gene and risk of gastric cancer in Chinese populations. Hum Genet 2012;131:1235-44.

21. $\mathrm{Hu} \mathrm{J}, \mathrm{Wu} W$, Zhu B, et al. Cerebral glioma grading using Bayesian network with features extracted from multiple modalities of magnetic resonance imaging. PLoS One 2016;11:e0153369.
22. Slater JM, Shih HA. Pseudoprogression in low-grade glioma. Transl Cancer Res 2019;8:S580-4.

23. Qu S, Qiu O, Huang J, et al. Upregulation of hsa-miR$196 a-5 p$ is associated with MIR196A2 methylation and affects the malignant biological behaviors of glioma. Genomics 2021;113:1001-10.

24. Zang L, Kondengaden SM, Che F, et al. Potential epigenetic-based therapeutic targets for glioma. Front $\mathrm{Mol}$ Neurosci 2018;11:408.

25. Li N, Cui Z, Huang D, et al. Association of LINC00673 rs11655237 polymorphism with cancer susceptibility: a meta-analysis based on 23,478 subjects. Genomics 2020;112:4148-54.

26. Li L, Peterson C, Legerski R. Sequence of the mouse XPC cDNA and genomic structure of the human XPC gene. Nucleic Acids Res 1996;24:1026-8.

27. Peng Q, Lao X, Tang W, et al. XPC Lys939Gln polymorphism contributes to colorectal cancer susceptibility: evidence from a meta-analysis. Diagn Pathol 2014;9:120.

28. Yoshino Y, Takeuchi S, Katoh T, et al. XPC intron $11 \mathrm{C} / \mathrm{A}$ polymorphism as a risk factor for prostate cancer. Environ Health Prev Med 2016;21:100-4.

29. Zhu LB, Xu Q, Hong CY, et al. XPC gene intron $11 \mathrm{C} / \mathrm{A}$ polymorphism is a predictive biomarker for the sensitivity to NP chemotherapy in patients with non-small cell lung cancer. Anticancer Drugs 2010;21:669-73.

30. Hua RX, Zhuo ZJ, Shen GP, et al. Polymorphisms in the XPC gene and gastric cancer susceptibility in a Southern Chinese population. Onco Targets Ther 2016;9:5513-9.

31. Gil J, Ramsey D, Stembalska A, et al. The C/A polymorphism in intron 11 of the XPC gene plays a crucial role in the modulation of an individual's susceptibility to sporadic colorectal cancer. Mol Biol Rep 2012;39:527-34.

32. Mathew S, Abdel-Hafiz H, Raza A, et al. Host nucleotide polymorphism in hepatitis $\mathrm{B}$ virus-associated hepatocellular carcinoma. World J Hepatol 2016;8:485-98.

33. Zhu Y, Yang H, Chen Q, et al. Modulation of DNA damage/DNA repair capacity by XPC polymorphisms. DNA Repair (Amst) 2008;7:141-8.

34. Chavanne F, Broughton BC, Pietra D, et al. Mutations in the XPC gene in families with xeroderma pigmentosum and consequences at the cell, protein, and transcript levels. Cancer Res 2000;60:1974-82.

35. Yasuda G, Nishi R, Watanabe E, et al. In vivo destabilization and functional defects of the xeroderma pigmentosum $\mathrm{C}$ protein caused by a pathogenic missense 
mutation. Mol Cell Biol 2007;27:6606-14.

36. Khan SG, Muniz-Medina V, Shahlavi T, et al. The human XPC DNA repair gene: arrangement, splice site information content and influence of a single nucleotide polymorphism in a splice acceptor site on alternative splicing and function. Nucleic Acids Res 2002;30:3624-31.

(English Language Editor: J. Jones)

Cite this article as: Zhang Z, Huang Y, Chen H, Wu P, Deng Z, Deng G, Zheng Y, Li G, Yuan L, Xu Y. The correlation between polymorphisms in the XPC gene and glioma susceptibility in a Chinese pediatric population. Transl Pediatr 2021;10(7):1896-1904. doi: 10.21037/tp-21-301 


\section{Supplementary}

Table S1 Frequency distribution of selected variables in glioma patients and cancer-free controls (37)

\begin{tabular}{|c|c|c|c|c|c|}
\hline Variables & \multicolumn{2}{|c|}{ Cases $(n=171)$} & \multicolumn{2}{|c|}{ Controls $(n=228)$} & $\mathrm{P}^{\mathrm{a}}$ \\
\hline Age, months & & & & & 0.623 \\
\hline Range & \multicolumn{2}{|c|}{$4.00-168.00$} & \multicolumn{2}{|c|}{$4.00-168.00$} & \\
\hline Mean \pm SD & \multicolumn{2}{|c|}{$63.40 \pm 47.72$} & \multicolumn{2}{|c|}{$52.41 \pm 32.65$} & \\
\hline$\geq 60$ & 86 & 50.29 & 109 & 47.81 & \\
\hline Gender & & & & & 0.190 \\
\hline Female & 81 & 47.37 & 93 & 40.79 & \\
\hline Male & 90 & 52.63 & 135 & 59.21 & \\
\hline \multicolumn{6}{|l|}{ Subtypes } \\
\hline Ependymoma & 24 & 14.62 & - & - & \\
\hline Neuronal and mixed neuronal-glial tumors & 14 & 8.19 & - & - & \\
\hline Embryonal tumors & 7 & 4.09 & - & - & \\
\hline \multicolumn{6}{|l|}{ WHO stages } \\
\hline 1 & 103 & 60.23 & - & - & \\
\hline II & 28 & 16.37 & - & - & \\
\hline III & 15 & 8.77 & - & - & \\
\hline IV & 25 & 14.62 & - & - & \\
\hline
\end{tabular}

${ }^{a}$, two-sided $\chi^{2}$ test for distributions between glioma patients and cancer-free controls. SD, standard deviation.

\section{References}

37. He J, Yuan L, Lin H, et al. Genetic variants in m6A modification core genes are associated with glioma risk in Chinese children. Mol Ther Oncolytics 2021;20:199-208. 